\title{
Expansión del regadío tradicional y control local en la Real Acequia de Moncada
}

\author{
Vicente Sales Martínez, Mar Ortega-Reig y Guillermo Palau-Salvador \\ Universitat Politècnica de València \\ sequiola2000@gmail.com,marorrei@upv.es, guipasal@agf.upv.es
}

\begin{abstract}
Resumen. Son numerosos los ejemplos de sistemas de riego que han sido capaces de auto-gestionar el agua como un recurso comunal a largo plazo y en condiciones de marcada escasez, entre ellos el de la Comunidad de Regantes de la Real Acequia de Moncada (RAM), con 5000 ha y 13000 propietarios que gestionan de forma colectiva los recursos hídricos del río Turia. Ostrom (1990), basándose en el caso de la Huerta de Valencia, propuso varios principios asociados al éxito de la gestión comunal. El objetivo de este trabajo es revisar dos de ellos (a) la existencia de límites claramente definidos y (b) la capacidad de los usuarios de modificar las normas de operación, para el caso de la RAM, basándonos en la consulta de archivos históricos. Los resultados muestran que, pese a que el espacio regado no ha permanecido totalmente constante, sí que han existido unos límites prefijados que han permitido mantener una relación entre tierra regable y disponibilidad de recursos que se ha adaptado a las necesidades de los usuarios y donde es destacable la importancia de la gestión y toma de decisiones a escala local.
\end{abstract}

Palabras clave: riego, gestión colectiva, expansión del riego, derechos de riego, extremal.

\begin{abstract}
There are wide arrays of examples of irrigation systems that have been able to self-manage water as a common resource in the long term and in severe scarcity conditions. One of them is the Real Acequia de Moncada (RAM) Irrigators Community, with 5000 ha and 13000 owners who collectively manage water resources from the Turia River. Ostrom (1990), based in the case of the Huerta of Valencia, proposed several principles associated to the success of collective management. The objective of this work is to analyze two of them for the case of the RAM, (a) the presence of clearly defined boundaries and (b) capacity of users to modify operational rules. We contrast these principles with the information of historical archives. We show that limits have existed, allowing maintaining a relation between irrigated land and resources, and adapting to users' needs. Local management and decision making has been also of remarkable importance.
\end{abstract}

Keywords: irrigation, collective management, irrigation expansion, water rights, extremal.

\section{Introducción}

Son numerosos los ejemplos de sistemas de riego que han sido capaces de auto-gestionar el agua como un recurso comunal a largo plazo y en condiciones de marcada escasez. Muchos de estos sistemas han superado con éxito los desafíos inherentes a esta gestión comunal. Uno de los sistemas más famosos ha sido el sistema de riego de la Huerta de Valencia, donde la Real Acequia de Moncada (RAM) es, debido a su extensión, la Comunidad de Regantes de mayor relevancia en este espacio irrigado. Este sistema cubre más de 5000 ha (Figura 1), donde el minifundio está ampliamente extendido ya que el sistema comprende a más de 13000 propietarios (el 95\% tiene menos de 1 hectárea) que gestionan de forma colectiva los recursos hídricos del río Turia ${ }^{1}$.

\footnotetext{
${ }^{1}$ El sistema de riego de la acequia de Moncada se extiende a un conjunto de 30 lugares y municipios: Borbotó, Benimamet, Massarrojos, Benifaraig, Carpesa, Mahuella, Teuladella, Rafalell, Vistabella, casas de Bárcena (actuales pedanías de la ciudad de Valencia), Paterna, Quart, Burjassot, Godella, Rocafort, Moncada, Alfara, Vinalesa, Foios, Almàssera, Meliana Albalat, Albuixec, Massalfassar, Museros, Massamagrell, Pobla de Farnals, Rafelbunyol, El Puig y Puçol.
} 
Ostrom $(1990,2011)$ identifica ocho principios comunes a los casos de instituciones que han solucionado con éxito los problemas de gestión comunal de los recursos naturales, basándose entre otros ejemplos en el de la huerta valenciana. Estos problemas de gestión comunal son, según la autora, (a) la provisión de un nuevo conjunto de instituciones, (b) el establecimiento de compromisos creíbles entre los usuarios, y (c) el problema de la supervisión mutua. La dificultad radica en que estos dilemas se encuentran anidados, es decir, sin resolver el problema de la supervisión mutua, no se puede lograr un compromiso creíble y en consecuencia no hay incentivos para proponer nuevas reglas de gestión o instituciones (Ostrom 1990, p. 45).
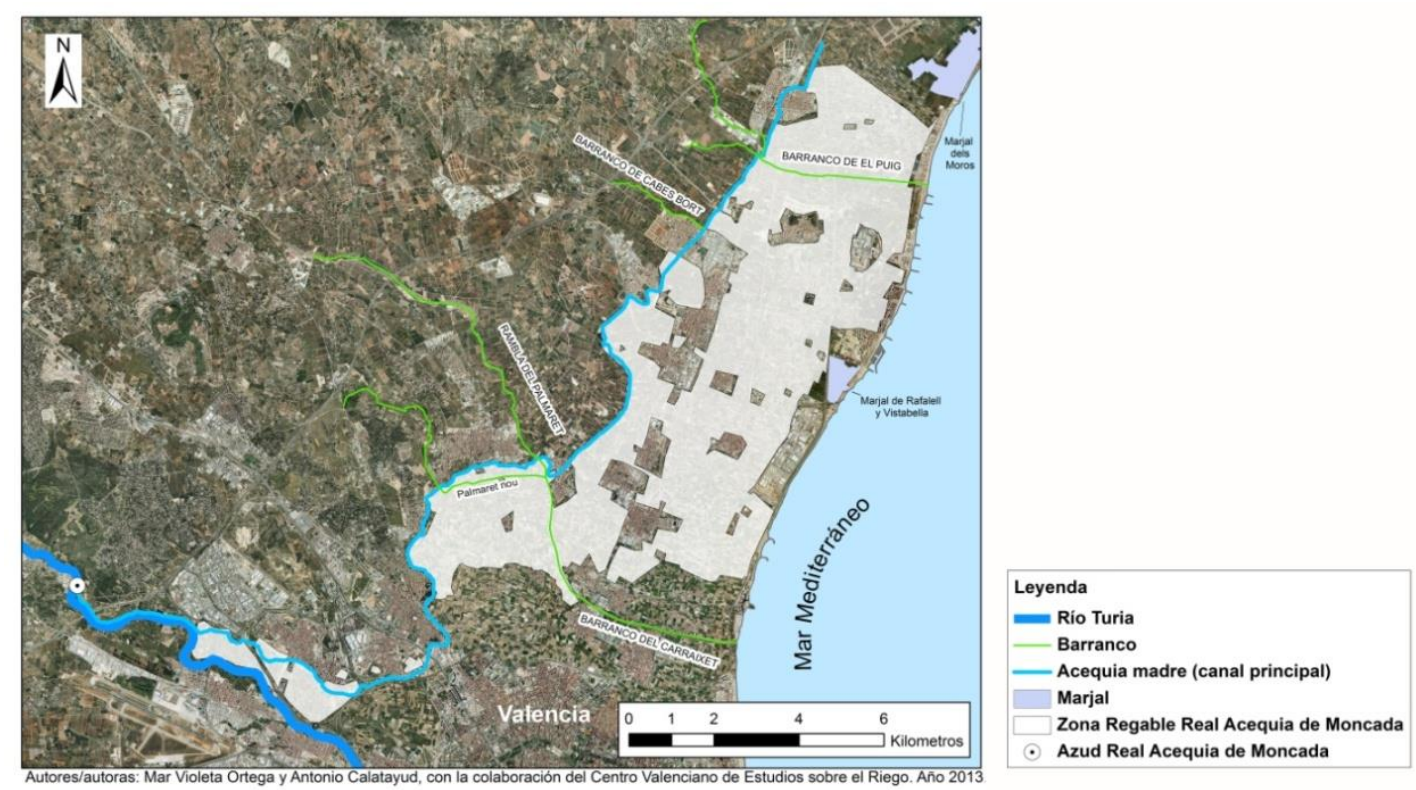

Fig. 1. Superficie regable de la Real Acequia de Moncada en 2010.

Cabe destacar que aunque la organización e instituciones de este sistema de riego ya llamaron la atención a Jaubert de Passa (1823), que transcribió sus ordenanzas. El trabajo de Ostrom sobre los regadíos valencianos se basa en los estudios previos de Maass y Anderson (1978), y Glick (1970). No obstante, algunas características que Ostrom identifica como principios de gestión en el caso de la huerta de valencia, han sido discutidas a la luz de otros trabajos históricos (Garrido, 2011a, 2012).

El objetivo de este trabajo es analizar en detalle la aplicación de dos de los principios citados por Ostrom $(1990,2011)$ : (a) la existencia de límites claramente definidos y (b) el uso de acuerdos colectivos que permitan participar a los usuarios en la modificación de las normas, al caso de la Real Acequia de Moncada. No obstante, entendemos que estos principios son una herramienta útil como marco para el análisis del caso y no recomendaciones a seguir para la gestión comunal. Hay que destacar que cuando analizamos en detalle, para un caso específico, estos principios de diseño, en cuyo espíritu está lograr un grado de generalización y abstracción suficiente que permita la comparación entre casos, las incongruencias y matices con la realidad son indiscutibles. 


\subsection{Contexto histórico de la creación del espacio regado}

El sistema de regadío de la RAM remonta su origen al poblamiento del territorio valenciano (Xarq al-Andalus) por tribus bereberes procedentes del norte de África a partir del siglo VIII , dentro del proceso general de expansión islámica (Torró, 2012).

Los primeros regadíos debieron originarse a partir de la utilización de las aguas autóctonas: fuentes, ullals, pequeñas ramblas, para ya en el siglo $\mathrm{X}$ dar paso a la construcción de un gran sistema de irrigación basado en el uso de las aguas derivadas del río Turia. La creación del sistema pudo obedecer bien a decisiones, dentro de un proceso colaborativo, entre las distintas alquerías, o a una decisión emanada de un poder político centralizado en la ciudad islámica de Valencia

Tras la conquista cristiana en los albores del siglo XIII se procedió a una sustitución de la población andalusí por colonos cristianos (Torró, 2000). El complejo proceso, supuso la medición, sogejament, y reparto, repartiment, de los espacios agrícolas y el asentamiento de los colonos en los espacios habitacionales abandonados por los andalusís (alquerías). Los nuevos pobladores, dentro de un contexto definido por el nuevo orden feudal, expandirán, de forma progresiva, el regadío por todo el espacio disponible, es decir, aquel situado por debajo de la línea de rigider ${ }^{2}$ que constituye el canal de Moncada, con las limitaciones de cota impuestas por el riego por gravedad, y los espacios, posiblemente suelos hidromorfos, imposibles de cultivar con la tecnología propia del momento.

La primera mención de este espacio regado aparece en el año 1239, en el Llibre dels Privilegis de València (Fuero XXXV), donde el Rey Jaume I se reserva "[...] la acequia real que va a Puçol...”. Además, ya sabemos que en el año 1240 el canal de la RAM llegaba hasta El Puig y Puçol para dar riego a ambos términos, como se recoge en la Carta de Amojonamiento de los términos de Pusol i Enesa ${ }^{4}$ (actualmente El Puig).

\section{Metodología}

Para la realización de este análisis se han consultado la documentación (datos de crecimiento, evolución y gestión del espacio regado, así como las actas) del Archivo de la Real Acequia de Moncada (ARAM) y los archivos municipales de los municipios con tierras incluidas dentro del espacio regado por la acequia de Moncada.

\section{Resultados y discusión}

Los resultados se estructuran en dos apartados, en el primero se tratan los temas ligados a la existencia de límites claramente definidos, y en el segundo los ligados al principio sobre el uso de acuerdos colectivos que permitan participar a los usuarios en la modificación de las normas.

\footnotetext{
${ }^{2}$ Línea de rigidez: término acuñado por Barceló (1996) para designar una línea imaginaria bajo la que se establece la irrigación por gravedad, sin posibilidad de ser acrecentada.

3 "De servitut daygua e daltres coses" [fuero XXXV, rubrica XVI], en: Fori... (1990): I, IX (r)

${ }^{4}$ Archivo de la Catedral de Valencia. Carta de Amojonamiento de los términos de Puzol y Enesa, pergamino 2372 (noviembre, 1240), copia del siglo XIV.
} 


\subsection{La existencia de fronteras claramente definidas y delimitación de los usuatios que pueden usar los recursos comunales}

Este principio permite definir quién no tiene derecho al uso del recurso comunal y permite emprender acciones contra él. Si el acceso no se limita, se puede producir la sobreexplotación del recurso (Hardin, 1968). En el caso del riego con aguas superficiales, la expansión descontrolada del sistema de riego (en ausencia de otras medidas) supondría, más que la sobrexplotación, la imposibilidad de disponer de una cantidad mínima que permitiera la supervivencia de las cosechas de los diferentes usuarios en situaciones de escasez de agua.

Según Garrido (2011a), salvo contadas excepciones en las comunidades de regantes del este de España, esta cuestión se resuelve de forma indirecta, delimitando la superficie con derechos de riego, y como el derecho al agua va ligado a la tierra, los usuarios que tienen acceso al recurso son aquellos que tienen o arriendan tierra de huerta. Si una comunidad permitiera un crecimiento elevado en relación a los recursos disponibles, resultaría en una menor disponibilidad de agua por unidad de superficie. No obstante, si prestamos atención al sistema de reparto del agua, que es un mixto de tanda y turno ${ }^{5}$, en caso de escasez no se dispone de menor cantidad de agua por unidad de superficie sino que se alarga el tiempo entre riegos. Esto ocurre porque el derecho al uso del agua se basa en que la frecuencia de riego sea igual para todos los usuarios (Trawick et al., 2014).

3.1.1 Los derechos históricos de agua en las tierras de la Real Acequia de Moncada. Para que haya límites tiene que haber sub-conjuntos espaciales reconocidos (Ruf 2011). Las tierras de la RAM se han dividido históricamente en dos sectores en función de sus derechos de aguas (Sales Martínez 1986, 1988, 2000), esta situación es similar a la que sucede en otros puntos de la huerta (Burriel de Orueta, 1971, Glick, 2007, Sanchis Ibor, 2001). Por un lado, las tierras de jovedat han tenido históricamente derecho prioritario sobre el uso de las aguas derivadas del río Turia. Por otra parte, las tierras de extremal disponían históricamente de derecho al uso de las aguas sobrantes tras el riego del jovedat, recursos que se complementaban con el aprovechamiento de recursos hídricos autóctonos: fuentes, minas de agua, aceñas o sénies y manantiales o ullals.

De la documentación conservada en el Archivo de la RAM (ARAM) podemos extraer ejemplos concretos de la diferencia de derechos sobre el agua de los distintos espacios. En la controversia que enfrenta en 1944 a la RAM y a la Comunidad de Regantes del Canal del río Turia (Acequia del Oro) ${ }^{6}$ se plantea el uso de los caudales sobrantes del río entre ambas comunidades; la de Moncada adujo que esa agua era derecho de su extremal,pues tiene derecho a aguas sobrantes y arguye, que la tierra de extremal viene siéndolo desde tiempo inmemorial y por tanto, muy anterior al 12 de febrero de 1829 (fecha de constitución Comunidad de Regantes del Canal de Riegos del río Turia), por lo la RAM argumente que:

\footnotetext{
${ }^{5}$ En el clásico estudio de Maass y Anderson (1978), estos distinguen entre el sistema de turno y el de tanda. El caso de la RAM es, como en la mayoría de comunidades de regantes donde el agua está ligada a la tierra, una mezcla de ambas (Garrido 2011a, 2011b). Es decir, existen diferentes zonas de riego a las que se ha asignado un tiempo de riego (tanda) y dentro de cada zona de riego se utiliza el sistema de turno. Pese a que el turno puede verse interrumpido si finaliza el tiempo asignado a esa zona, cuando vuelva a haber agua en esa misma zona el riego. se retomará en el último campo que se ha quedado por regar. De esta forma, un regante en la cabecera del sistema no volverá a tener derecho a regar hasta que el resto de regantes haya tenido igualmente este derecho, incluidos aquellos en la cola del sistema.

${ }^{6} \mathrm{La}$ Acequia del Oro era la última que tomaba el agua del río Turia.
} 
"aquellos extremales nuestros, que los respectivos ayuntamientos de los pueblos tienen determinados, puesto que aprovechan nuestros sobrantes, tienen necesidad de ellos y deben defenderse lo poco que les llegue, por ser asi de razón y de justicia." >

En 1962, el síndico de Meliana de la RAM plantea una cuestión a resolver por la Junta de Gobierno: las aguas sobrantes de la RAM estaban siendo derivadas al extremal de la zona regable de la Comunidad de Regantes de la Acequia de Rascanya, uso que se hacía en perjuicio de las tierras de extremal de Meliana, que tenía derecho a ellas ${ }^{8}$, pues integraban el área regable. La RAM admite el planteamiento y resolvió que las aguas se recondujeran directamente a la zona regable del extremal de Meliana mediante la construcción de un nuevo canal ${ }^{9}$ que evitó que los caudales sobrantes fueran a la Acequia de Rascanya.

Parece lógico pensar que las tierras de jovedat representan la superficie regada en el momento de creación de la Comunidad de Regantes, y han tenido históricamente derecho prioritario sobre el uso de las aguas derivadas del río Turia, y sobre ellas se cargaban exclusivamente los gastos. Por otro lado, las tierras de extremal constituyen espacios puestos en regadío con posterioridad, (como por ejemplo los marjales, que requerían la inversión en un sistema de drenaje).

Los ejemplos anteriores dejan constancia de la gestión del espacio de extremal por parte de la RAM a mediados del siglo XX. Como veremos en los apartados siguientes, las tierras de extremal se gestionaron inicialmente a escala municipal y eran consideradas por la RAM como externas al sistema. Esta gestión local del extremal (o en algunos casos ausencia de gestión) va a ser transferida, a lo largo del siglo XX, a la RAM.

3.1.2 Ampliación de las zonas con derecho prioritario. La causa de que determinados espacios situados dentro del área regable del canal de Moncada tuvieran un derecho prioritario y otros no, hay que buscarla en la gestión colectiva del propio sistema (Ostrom 1990, 2011).

Además, la posibilidad de conceder derecho prioritario y derecho a sobrantes es un requisito social, pues si con un caudal finito, se repartieran ilimitados derechos, eso resultaría en un prejuicio para todos los usuarios, especialmente en situaciones de sequía, ya que no podrían acceder a la cantidad mínima de recurso necesaria para asegurar la viabilidad de las cosechas por haber invertido recursos en el riego de una mayor superficie. En este sentido, la existencia de derechos prioritarios y no prioritarios forma parte de la gestión y sostenibilidad del sistema pues permite adaptarse a la estacionalidad de los ríos mediterráneos. Esta situación que podríamos denominar de sequía recurrente, genera un modelo organizativo que persigue básicamente el control de la sequía y la adaptación a la irregularidad de los ríos (Garrido, 2012).

Esta necesidad de poner obstáculos a la expansión era frecuente en la mayoría de comunidades de regantes españolas, llegando incluso en algunos casos a tener una superficie menor de la que podrían haber asumido con los recursos disponibles (Garrido, 2011a, 2012). Estas restricciones no impidieron el crecimiento de los regadíos, en algunos casos a muy largo plazo, paulatinamente y sin que quienes ampliaban el riego lo hicieran con autorización alguna, en otros casos este crecimiento superficial tuvo lugar de forma más abrupta y

\footnotetext{
7 ARAM. Escrito unido al Acta de la Junta de Gobierno de la RAM del 14/07/1944.

${ }^{8}$ ARAM. Acta de la Junta de Gobierno de la RAM del 4/12/1962.

${ }^{9}$ ARAM. Acta de la Junta de Gobierno de la RAM del 4/12/1963.
} 
con la oposición de parte de los regantes (Garrido, 2012). Las huertas que crecieron por encima de los recursos disponibles, lo hicieron a costa de perder intensidad en el cultivo. Garrido (2012) sugiere una cierta estabilidad de las superficies regadas en las huertas tanto del curso bajo del río Turia como en las del río Mijares, fruto de un pacto entre las comunidades que las conforman y según el cual se habría prefijado un tamaño máximo de las mismas que no habría sido cubierto hasta la expansión del regadío de mediados del siglo XIX. Esta afirmación cabe matizarla al menos en el caso que nos ocupa. En la RAM la supuesta estabilidad, al menos estadística, que muestra a lo largo de varias centurias la superficie regada de pleno derecho, no es sino una ficción fruto de la ocultación ${ }^{10}$ ejercida por los poderes locales; las parcelas irrigadas se multiplicaron, si bien este crecimiento, ocultado, no se oficializó hasta bien entrado el siglo XX, poco tiempo antes del momento en que se produjo la transferencia, por parte de los ayuntamientos y con pleno derecho, de las tierras extremales que se incorporaron así a la RAM y que venían históricamente siendo consideradas como externas al sistema.

El advenimiento de la $2^{a}$ República implicó un cambio importante en la composición política de los ayuntamientos y, en consecuencia, un cambio en la estructura de los poderes fácticos tradicionales marcados por las oligarquías agrícolas locales que venían controlando el poder local y por ende el poder dentro de la Junta de Gobierno de la RAM. Es durante el período republicano cuando la RAM realiza trabajos que le permitirán conocer en detalle la superficie regada gracias a las aportaciones de su técnico Eduardo García Tarín desde 1927 hasta 1932. Este técnico realiza el "levantamiento topográfico y trazado del plano general del curso y zona regable de la Acequia de Moncada", y presenta a la RAM el "Proyecto de Fiscalización y Parcelación de las tierras regadas por la Real Acequia de Moncada", que cartografía y cuantifica los incrementos de superficie la regada dentro del jovedat y la extensión del extremal de la RAM. En 1934 la RAM ya emite los pliegos de cargo sobre las superficies reales del jovedat.

Así, terminada la Guerra Civil, y apoyándose en el trabajo previo realizado, la RAM empezó, tras del acuerdo de su Junta de Gobierno con los ayuntamientos incluidos en su zona regable, a emitir pliegos de cargo ${ }^{11}$ sobre las tierras de extremal ${ }^{12}$, parte de cuyos recursos hídricos, los provenientes de aguas subterráneas, venían sufriendo un continuo deterioro a causa del descenso generalizado del nivel freático (Sales Martínez, 1988).

Al aflorar en 1940 el extremal, este se empieza a incluir en la recaudación de los repartos (presupuesto ordinario y extraordinario). Durante unos años 1940-1946 existe una clara diferenciación en la imposición (Tabla 1: línea punteada). Desde 1947 a 1952 la imposición por el concepto de reparto ordinario se iguala, en tanto que la imposición por reparto extraordinario mantiene un diferencial entre jovedat y extremal. A Partir de 1953, tras la puesta

\footnotetext{
${ }^{10}$ En 1858 se planteo, por parte del Acequiero Mayor, la cuestión en la Junta de Gobierno de la RAM del 11 de Junio en estos términos: "que con arreglo a ordenanzas son seis mil trescientas noventa cabizadas las que deben regarse con el agua de la acequia de Moncada, y que no obstante ellos se están regando en el día muchísimas más, y que en algunos pueblos satisfacen el cequiaje con arreglo a los cupos que se les distribuyo, baciendo ya esta distribución desde inmemorial con arreglo a la expresada dotación, si bien en los indicados pueblos cobran el cequiaje por las cabizadas que en ella se riegan resultándoles por ello un beneficio que era indispensable remediar en obsequio de los fondos de la comuna" (ARAM).

${ }^{11}$ Los pliegos de cargo eran los documentos de recaudación emitidos por la Real Acequia de Moncada para notificar el importe de "tacha y cequiaje" a pagar por los ayuntamientos, como contribución al reparto de los costes de la acequia, en función de la superficie regable inscrita.

${ }^{12}$ El 4 de diciembre de 1939 la Junta de Gobierno de la RAM realiza el trámite y notifica a los respectivos ayuntamientos para iniciar el cobro del canon a los extremales, función que anteriormente delegaba en los ayuntamientos, pero es en la Junta de 24 de febrero del año 1940 cuando se ratifica el acuerdo tomado y empieza a surtir efecto (ARAM).
} 
en funcionamiento del embalse de Benagéber, las tarifas del jovedat y el extremal se igualaron. El derecho al agua del extremal, se convirtió, desde la regularización del río Turia, en un derecho igual, pasando a ser la distinción entre extremal y jovedat una mera distinción interna ${ }^{13}$.

Tabla 1. Evolución de los repartos ordinarios y extraordinarios de "tacha y cequiaje" (en pesetas por banegada) para las tierras de jovedat y extremal en la Real Acequia de Moncada de 1941 a 1953.

\begin{tabular}{ccccc}
\hline ANO & $\begin{array}{c}\text { Presupuesto } \\
\text { Ordinario } \\
\text { jovedat }\end{array}$ & $\begin{array}{c}\text { Presupuesto } \\
\text { Ordinario } \\
\text { extremal }\end{array}$ & $\begin{array}{c}\text { Presupuesto } \\
\text { Extraordinario } \\
\text { jovedat }\end{array}$ & $\begin{array}{c}\text { Presupuesto } \\
\text { Extraordinario } \\
\text { extremal }\end{array}$ \\
\hline 1941 & 4 & 2 & - & - \\
1943 & 2 & $1(1,25)$ & 5,5 & $2,75(3,5)$ \\
1945 & 3 & 2 & 10 & 7 \\
1947 & 4 & 4 & 9 & 6 \\
1949 & 4 & 4 & 9 & 6 \\
1950 & 4 & 4 & 9 & 6 \\
1951 & 5 & 5 & 9 & 6 \\
1952 & 5 & 5 & 10 & 6 \\
1953 & 5 & 5 & 15 & 15 \\
\hline
\end{tabular}

La regulación de las aguas del río Turia, iniciada con la construcción del embalse de Buseo (1915) y continuada con las de construcción del embalse de Benagéber (1933-1955) y de Loriguilla (1967) permitieron asegurar los riegos, especialmente los primaverales y estivales, y garantizar el suministro en igualdad de condiciones a todas las tierras situadas bajo la cota del canal de Moncada. La restricción de derechos prioritarios que encorsetaba el sistema, pudo por fin ser liberada. No fue el incremento de la dotación, ni la ampliación en la capacidad de transporte del canal, sino el aumento en la seguridad en el abastecimiento junto con las obras de mejora realizadas en el canal principal (revestimiento del cajero, introducción de nuevas paradas o quadrats, etc.), lo que propició la extensión del uso prioritario del agua al total de los espacios situados bajo la cota del canal ${ }^{14,15}$. No obstante, y no es cuestión baladí, el jovedat continuó reservándose como propias las aguas del río Turia en su, ahora ya hipotético, régimen natural, es decir, sin regular; hasta ese punto permanecía interiorizado el principio de autocontención: en un hipotético regreso al régimen natural del Turia -por una catástrofe o por cualquier causa que desregularizara el régimen del río- las aguas volverían a ser derecho prioritario del histórico jovedat.

\footnotetext{
${ }^{13}$ ARAM. Acta de la Junta de Gobierno de la RAM del 5/05/1977 y del 5/02/1988.

${ }^{14}$ ARAM. Acta de la Junta de Gobierno de la RAM del 30/12/1966 y del 4/03/1967.

${ }^{15}$ En 1977 se produce la inscripción de aprovechamiento en el Registro Central de Aprovechamientos y así, en Junta de Gobierno de la RAM del 6/10/1977 se hace constar que: "según resolución de fecha 28 de julio del corriente año, habiéndose asegurado un caudal continuo de 5.716’36 lts/s para las 7.083 Hectáreas que riega la Comunidad, incluido el chovedat y el extremal; pero según se dice en la propia resolución se ha de instruir otro expediente complementario para determinar las dotaciones anuales correspondientes a los derechos tradicionales y procedentes de la regulación como consecuencia de los planes del Estado. Añade el Presidente que en virtud de tal inscripción las tierras de extremal adquieren el derecho a regar con las aguas fluyentes del río que no utilice el chovedat, completándose las deficiencias con las aguas embalsadas.”
} 
3.1.3 Evolución de la recaudación del cequiaje y concesión de derechos de agua. Las ampliaciones de la superficie regada, realizadas en época feudal a partir de los preexistentes regadíos islámicos, se sucedieron de forma paulatina debido a la conversión de espacios imbricados en la superficie regable, a la puesta en riego de alters ${ }^{16} \mathrm{y}$ desecación de marjales a lo largo de varios siglos. La incorporación paulatina de esas tierras (sobretodo secanos y alters) necesitó de sucesivos readrezos, consistentes en la reorganización interna del riego del canal que busca favorecer el reequilibrio del reparto justo del agua tras de un período de crecimiento de la superficie regada y que implicaban la variación de las condiciones de funcionamiento hidráulico del canal.

Para el reparto del cequiaje, la RAM giraba un pliego de cargo anual al municipio por la superficie registrada. La asignación de superficies a cada villa, común o lugar hunde sus raíces en plena época medieval, y podemos considerarla como cerrada en el siglo XVI (Sales Martínez et al. 2011). El incremento de las superficies regadas no se trasladó a la administración de la RAM, y durante siglos no se actualizó. El desfase beneficiaba a los municipios que, encargados del cobro, lo aplicaban al total real de parcelas regadas. Es lo que sucede en el Ayuntamiento de Benifaraig en 1902, la RAM reclama el pago de 1188 hanegadas y el ayuntamiento emite un reparto de gastos del cequiaje para 1297 hanegadas (incrementando además la cuota por hanegada). La diferencia de ingresos obtenida debido a la mayor cuota y superficie gravada se destina a jornales de escuras y mondas (43\%), formación del reparto de cequiaje $(22 \%)$, cambio de calderilla y material (5\%), premio de cobranza al $1 \%(17 \%)$, fallidos y custodia de aguas $(13 \%)$.

La diferencia en la recaudación dentro del jovedat se sustentaba, como ya hemos indicado, en un proceso de ocultación de las autoridades locales frente a la RAM ; ocultación que permitía al municipio disponer de una partida presupuestaria adicional para hacer frente a diferentes gastos municipales, en algunos municipios a esta partida se le denomina fondo de cequiaje. En Vinalesa, entre 1920 y 1923, y muy probablemente en otros municipios, este fondo de cequiaje se destinaba parcialmente a gastos generales del Ayuntamiento (maestros, alumbrado público, gastos de fiesta y liturgia, material de seguridad y vigilancia, gratificaciones por trabajos extraordinarios de vigilantes de campo) ${ }^{17}$, también se sufragaban los gastos ligados al mantenimiento del sistema de riego (supervisión escuras, reparación y limpieza de acequias, etc.).

El desfase administrativo continuó vigente hasta el inicio de los años sesenta del siglo XX, probablemente favorecido por el hecho de que los síndicos, representantes de los regantes en la RAM, fueran, generalmente, alcaldes o concejales, y, por tanto, con poco interés en modificar el desfase de caja en prejuicio de las arcas municipales y a favor de la Comunidad de regantes. En los archivos municipales consultados aparecen con cierta asiduidad referencias a autorizaciones municipales para la puesta en riego de determinadas parcelas en sus términos respectivos que nunca pasaron a incrementar las superficies registradas en la RAM. En Paterna, en 1895 se concede a dos usuarios la autorización para la prolongación

\footnotetext{
${ }^{16}$ Espacios próximos al canal principal y de mayor dificultad de riego por su elevada cota.

${ }^{17}$ Este caso no dista mucho de la gestión actual del agua a nivel municipal, donde el negocio de la gestión del agua no es espacialmente transparente, porque el agua, no solo paga el agua. Además, resulta difícil para las propias administraciones controlar el servicio que delegan en empresas privadas, a cambio de importantes sumas por la concesión del servicio. Un ejemplo paradigmático de esto es el caso de Montpellier, donde la cantidad recibida por la concesión de agua como 'derecho de entrada' en 1989 permitió, al entonces alcalde Georges Frêche, pagar los sobrecostes de la construcción del Palacio de Congresos de Montpellier, el Corum. Este 'derecho de entrada' ha sido desde entonces reembolsado por los usuarios en la factura del agua, con una tasa de interés estimada de aproximadamente el 7\% (Eau Securs 34, 2014).
} 
de un riego ${ }^{18}$. En Massamagrell en 1909, se autoriza al riego de un huerto, pasando a pagar cequiaje y costeando la construcción de la acequia correspondiente ${ }^{19}$. En 1928 en Paterna se crea una comisión para averiguar las hanegadas que no pagan e incluirlas ${ }^{20}$. Situaciones similares se presentan en Puçol (1940y 1948) ${ }^{21,22}$.

Los extremales se incorporaron al riego de derecho de la RAM de forma más abrupta, pero también más consensuada. En casi todos los municipios al norte del Barranco del Carraixet el límite entre el jovedat y el extremal venía marcado por una línea de parcelas bastante regular (Sales Martínez 1988) situada, por lo general, en la cota de los 10 msnm.; El Puig constituía una excepción y en su término las parcelas de jovedat y de extremal se yuxtaponían formando un complicado puzle que, ocasionalmente, generaba problemas en el orden del riego, lo que condujo, en ocasiones, a dotar a las parcelas de extremal de los derechos propios de las de jovedat, así sucede en 1950 cuando se autoriza a tres propietarios de campos de extremal a regar de jovedat, como lo hacen los campos situados arriba y debajo de estos, alegando "que motiva que se les quite el agua cuando riegan por los colindantes por alegar mejor derecho ocasionando situaciones de much a gravedad que pudieran ser de fatales consecuencias.” ${ }_{23}$ En 1962 y 1963 también se autoriza a dos campos de secano de la misma zona (partida del Castell) a que pasen a ser de regadío, abonando mil pesetas por hanegada al fondo de cequiaje ${ }^{24}$. La superficie de tierras consideradas extremal de la RAM era realmente importante; así, cuando en 1940 se hacen explícitas por primera vez las superficies de jovedat y extremal, estas contabilizaban respectivamente 46542 hanegadas (3878.5 ha) y 28853 hanegadas (2404.4 ha). La incorporación del extremal supuso incrementar en algo más del $38 \%$ la superficie con derecho al riego.

El hecho de que el extremal se igualara en cargas de cequiaje al jovedat, y que adquiriera el derecho al uso del agua de la RAM, no implicó, como ya hemos resaltado en el punto anterior, una absoluta igualación de derechos, el jovedat continuó, de hecho continúa, ostentando un derecho preferente a las aguas fluyentes, y en determinadas circunstancias esta distinción podría volverse aplicar (este caso es bastante hipotético, ya que la propia RAM se ha despreocupado de conservar la información relativa a esta diferenciación, información que ha desaparecido probablemente a causa de la equiparación de cequiaje y derechos entre el jovedat y el extremal). Así, a partir de cierto momento, alrededor de 1960, se admite la conversión de ciertas parcelas de extremal en jovedat, para compensar la pérdida de espacios de jovedat debidas al crecimiento urbano, siempre dentro de la misma derivación de riego. En 1960, tenemos constancia de este caso en Puçol, pues el ayuntamiento pide la baja de 89 hanegadas de jovedat por haber sido edificadas, fenómeno que ocurre en prácticamente todas las poblaciones y conlleva una merma de los recursos económicos para la Comunidad. En consecuencia, a partir de este momento la Junta de Gobierno acuerda que "automáticamente se incorpore al chovedat una cabida igual de la zona de extremal, del mismo roll o fila que la que causó la baja [...] las incorporaciones al chovedat lo serán de momento con carácter provisional y cada cinco años se revisará el plano y la zona incorporada para acordar si asi procede, la incorporación con carácter definitivo." ${ }^{25}$ Situaciones similares se presentan en Museros ${ }^{26}$, Massamagrell ${ }^{27}$ en

\footnotetext{
18 Archivo Municipal de Paterna, Acta municipal del 20/01/1895.

${ }^{19}$ Archivo Municipal de Massamagrell, Acta municipal del 17/08/1909.

${ }^{20}$ Archivo Municipal de Paterna, Acta municipal del 10/3/1928.

${ }^{21}$ Archivo Municipal de Puçol, Acta municipal del 1/8/1940.

${ }^{22}$ Archivo Municipal de Puçol, Acta municipal del 8/4/1948.

${ }^{23}$ Archivo Municipal de El Puig, Acta municipal del 16/05/1950.

${ }^{24}$ Archivo Municipal de El Puig, Acta municipal del 13/02/1962 y del 27/06/1963.

${ }^{25}$ ARAM. Actas de la Junta de Gobierno de la RAM del 13/2/1960.

${ }^{26}$ ARAM. Actas de la Junta de Gobierno de la RAM del 4/12/1961.

${ }^{27}$ ARAM. Actas de la Junta de Gobierno de la RAM del 19/10/1961.
} 
los años sesenta, situación que se prolonga en el tiempo, con autorizaciones de nuevas incorporaciones de parcelas, en este caso de secanos, en Museros en $1975{ }^{28}$ y en $1978{ }^{29}$, o en 1994 a condición de abonar 55.000 pesetas por hanegada ${ }^{30}$.

Prueba de esa discriminación positiva a favor del jovedat la tenemos cuando en 1960 se recibe una solicitud del Ayuntamiento de El Puig, para modificar el partidor del agua entre El Puig y Puçol, los motivos son que creen que la relación entre agua y tierra es justa cuando corresponde el riego al jovedat, pero que El Puig tiene perjuicios cuando se riega de extremal, por tener mayor zona regable de extremal que Puçol. La RAM contesta a El Puig, que las "tierras extremales tienen tan solo un derecho eventual y las aguas sobrantes las regula la Junta de Gobierno y su Presidente para el riego de extremales, sin norma fija, con arreglo a su criterio, según las necesidades del regadio, norma que ahora continuará vigente hasta que definitivamente se adopten medidas (definitivas) para el riego de las tierras extremales de la Comunidad." ${ }_{11}^{1} \mathrm{La}$ actitud de la RAM es similar a partir de 1960, cuando se empieza a tomar una postura activa para afrontar el problema recaudatorio y se empieza asumir la recaudación del cequiaje. Desde Puçol se traspasan los servicios de riego que se venían gestionando a escala municipal para que, tanto del jovedat como del extremal, sean ahora administrados por la RAM. No obstante, la RAM deja constancia de que algunas tierras mantienen su "carácter de extremales, o sea con derecho tan solo a regar con las aguas sobrantes." 32

Las precisiones anteriores muestran que el hecho de que haya unos límites físicos y sociales fijos, permite que los recursos de un territorio puedan ser objeto de políticas que garanticen que los esfuerzos de unos pocos no serán aprovechados por aquellos que no han contribuido inicialmente al sistema (Ruf 2011), es más en algunos casos se exige una contribución económica a modo de peaje de acceso.

Las autorizaciones de derechos continuaron decidiéndose desde los municipios hasta aproximadamente 1950. La explicación hay que buscarla en que hasta este momento la RAM funciona con el sistema mixto de tanda y turno (Maass y Anderson 1978), cada municipio tiene asignado un tiempo determinado por lo que la concesión de derechos a escala municipal no afecta al resto de regantes. Aunque no sabemos exactamente cuando ocurre (parece que entre 1940 y 1950), cuando la RAM cambia al sistema de turno, vigente en la actualidad, las decisiones de riego dentro de un término empiezan a afectar a todos los demás, por lo que parece que la RAM empieza a asumir competencias hasta ahora municipales. La RAM envía un oficio al Ayuntamiento de Meliana en 1942 en el que ordena se riegue "por turno riguroso", el ayuntamiento decide pedir una aclaración sobre las competencias que ha de tener en lo sucesivo el ayuntamiento en materia de riegos ${ }^{33}$.

En cuanto a la recaudación, podemos afirmar que antes de 1930 la tacha y cequiaje era recaudada por los municipios, tanto del jovedat como del extremal. Entre $1932^{34}$ y $1935^{35}$ tenemos constancia de un cambio profundo y la RAM da los pasos necesarios para pasar a

\footnotetext{
${ }^{28}$ ARAM. Actas de la Junta de Gobierno de la RAM del 6/3/1975.

${ }^{29}$ ARAM. Actas de la Junta de Gobierno de la RAM del 4/5/1978.

${ }^{30}$ ARAM. Actas de la Junta de Gobierno de la RAM del 14/7/1994.

${ }^{31}$ ARAM. Actas de la Junta de Gobierno de la RAM del 13/2/1960.

32 Archivo Municipal de Puçol, Acta municipal del 28/01/1960.

33 Archivo Municipal de Meliana, Acta municipal del 21/4/1942.

${ }^{34}$ El secretario de la RAM se lleva el padrón de Paterna para empezar a asumir la recaudación a partir de 1933 (Archivo Municipal de Paterna, Acta municipal del 25/5/1932).

${ }^{35} \mathrm{El}$ ayuntamiento que estaba a punto de realizar una derrama para gastos de la administración, junto con los gastos de cequiaje, pero debido a que se ha acordado en Junta de Gobierno de la RAM cobrar directamente la imposición de tacha y cequiaje, deciden girar tan solo el importe de la derrama (Archivo Municipal de Massamagrell, Acta municipal del 7/6/1935.)
} 
asumir esta gestión, en línea con el trabajo previo de Eduardo García Tarín. Hubo ciertas resistencias, como la de Vinalesa cuyo Ayuntamiento acuerda enviar un escrito a la RAM para que se abstenga de confeccionar el reparto del cequiaje ${ }^{36}$; en 1947 tenemos constancia de que el ayuntamiento de Meliana traspasa el cobro del cequiaje (tanto el de jovedat como el de extremal) a la Hermandad de Labradores ${ }^{37}$. Durante unos años existe cierta disparidad de comportamientos entre los distintos municipios en el cobro del extremal ${ }^{38}$, en tanto que la recaudación del jovedat es asumida por la RAM.

En 1986 el proceso había avanzado lo suficiente, como comprobamos al iniciarse los trámites para incluir la sindicatura de Puzol en la comunidad, lo que finalmente ocurre en 1987 39, ya que se menciona que se integre en las mismas condiciones que han hecho el resto de sindicaturas: "entregando las listas cobratorias, el catastro y haciéndose cargo la comunidad de la limpieza del canal principal en dicho término. De los demás asuntos dependientes de la Sindicatura, tales como, contrato con el recaudador, guarda y secretario, no se hará cargo la Comunidad, debiendo solucionarlos la sindicatura antes de la integración."

\subsection{Uso de acuerdos colectivos que permitan participar a los usuarios en la modificación de las normas}

Según este principio, la mayoría de individuos a quienes afectan las reglas de operación del sistema forman parte del grupo que puede modificar las reglas. Es decir, aquellos que están en contacto con los recursos y su uso, son quienes poseen la capacidad de adaptar las reglas a la situación local concreta, dentro de los límites del sistema y teniendo en cuenta que el coste del cambio tiene que ser compatible con las posibilidades económicas locales (Ostrom 1990, 2011, Ruf 2011).

3.2.1 Gestión local y modificación de las normas. Aunque la red de acequias de las tierras de extremal ha estado históricamente íntimamente ligadas al sistema de riego del jovedat, el control del riego de estos espacios periféricos ha contado con una gestión exclusivamente local. Este control o gestión local no fue exclusivo del extremal, también las cuestiones relacionadas con los riegos de tierras que gozaban de plenos derechos era, en gran medida, ejercida desde los propios municipios. Así sucede en Borbotó, que recaba información de la RAM sobre quien debía realizar la monda de acequias en el término; la respuesta de la RAM es:

Esta Junta de Gobierno de esta real Acequia de Moncada ninguna acequia tiene que limpiar ni mondar fuera de su canal pues del mismo toman su dotación las pequeñas comunidades de regantes. Ayuntamientos a los cuales incumbe la administración de la misma como también la monda y limpia de todos sus cauces, cobro del acequiage exacción de multas y demás [...]. ${ }^{40}$

El municipio de Massamagrell ejercía un férreo control de las actividades del riego dentro de su jovedat y su extremal. Es más, el ayuntamiento de esta 'pequeña comunidad de regantes' aprueba sus propias ordenanzas en 1901 para la gestión del riego. Las ordenanzas describen en su capítulo primero los recursos hídricos disponibles: las derivaciones de la

\footnotetext{
${ }^{36}$ Archivo Municipal de Vinalesa, Acta municipal del 28/2/1934.

${ }^{37}$ Archivo Municipal de Meliana, Acta municipal del 26/9/1947.

${ }^{38}$ Ciertos ayuntamientos delegaron el cobro en la Hermandades de Labradores y posteriormente en las Cámaras Agrícolas.

${ }^{39}$ ARAM. Junta de Gobierno de la RAM de los días 23/12/1986, 30/12/1986 y 7/4/1987.

${ }^{40}$ Archivo Municipal de Valencia, Actas municipales, documento N. ${ }^{\circ} 39$, caminos, 18/10/1890.
} 
RAM, las fuentes y los desagües municipales (que se declaran de interés general). En su capítulo $2^{\circ}$ se especifican las 'normas de conservación de acequias' donde además de especificar la responsabilidad de los regantes de hacer la monda según indique el ayuntamiento, se prohíbe realizar modificaciones del sistema de riego (nuevas derivaciones, ensanche de canales, etc.) sin autorización municipal y establece multas para los infractores. En el capítulo $3^{\circ}$ sobre la 'distribución de aguas', especifica que:

\section{Art. 481. La distribución de los riegos con las aguas procedentes de la Acequia mayor ó Real de Moncada, queda a cargo del Ayuntamiento. \\ Art.482. La ejecución de los acuerdos del Ayuntamiento, estará a cargo del Acequiero subalterno ó atandador quien á su vez. denunciará las infracciones ó extralimitaciones que se cometan en materia de riegos. \\ Art.485. Las infracciones en materia de riegos, serán castigadas por el Ayuntamiento y en conformidad á las prescripciones de las Ordenanzas de la Real Acequia de Moncada y Leyes municipal y de aguas. ${ }^{41}$}

Las ordenanzas de Massamagrell proveen normas para la administración del riego a escala local, es decir del uso del agua de la RAM dentro de los días de riego asignados al término de Massamagrell -lunes y jueves de la salida a la puesta del sol. Sin embargo, el caso de Massamagrell y Borbotó no parece una excepción, ya que las decisiones ordinarias asociadas a la gestión del riego han quedado reflejadas en las actas municipales de varios ayuntamientos. A escala municipal se tomaban decisiones ligadas a la gestión del agua. Por un lado decisiones relativas a la gestión económica: gastos de formación y recaudación del cequiaje, pago de la parte de este cequiaje exigida por la RAM, gastos de personal para la distribución del agua y gastos de mantenimiento del sistema de acequias. Por otro lado también se tomaban decisiones respecto a la gestión operativa: limpieza de acequias, autorización de obras, sanciones y multas.

Viendo el importante papel de las instituciones locales en el gobierno del riego, es lógico pensar que su papel debe ser también importante en la modificación de las nomas de riego. De hecho, existen varios ejemplos de modificación de las normas de riego a nivel municipal. En el caso de Meliana, por ejemplo, a resultas de la petición del ayuntamiento y los regantes del término, se designa en 1876 una comisión para modificar las dimensiones de dos acequias en un partidor de agua, en función del número de hanegadas regadas por cada brazo $^{42}$. En 1879, reunidos el ayuntamiento y los regantes acuerdan aplicar restricciones por cultivos como medida frente a la escasez de agua, en concreto "poner el agua a la mitad del rastrojo [barbecho] dejando las verduras a 17 días", acordando que se aplicaría la misma medida en caso de escasez en años venideros ${ }^{43}$. En $1916^{44}$ y en 1932 se acuerda como medida de escasez poner el agua al tall arreu o al tall a ran, respectivamente, especificando que el que deje pasar el turno del agua, no tendrá derecho a regar hasta que le vuelva a tocar por turno, añadiendo en 1932 que "no se dará el agua para las plantadas como se hacía antes." ${ }^{45}$ En el caso de Puçol, el ayuntamiento actúa sobre el orden de riego y aprueba:

\footnotetext{
${ }^{41}$ Archivo Municipal de Massamagrell. Actas municipales del 1/12/1901.

${ }^{42}$ Tras estudiar la comisión las hanegadas regadas por cada derivación decide: "Que el Brazo Bajo las Muelas que riega 1094 hanegadas le corresponden cincuenta y nueve centímetros $(59 \mathrm{~cm})$ de latitud y el del Trestelladot que riega 750 banegadas le corresponden cuarenta y un centímetros $(41 \mathrm{~cm})$ ". La relación para el reparto del agua entre hanegadas y centímetros es idéntica en ambos casos, de 18 hanegadas por cm de 'latitud' (Archivo Municipal de Meliana, Acta municipal del 26/12/1876).

${ }^{43}$ Archivo Municipal de Meliana, Acta municipal del 21/06/1879.

${ }^{44}$ Archivo Municipal de Meliana, Acta municipal del 16/04/1816.

45 Archivo Municipal de Meliana, Acta municipal del 1/04/1832.
} 
"Modificar las normas de riego de la buerta en el sentido, que puesta el agua en la primera fila (primer brazo) no podrá pasar al segundo hasta que haya terminado el riego de todas las tierras afectadas en el primer brazo, igual sistema regirá en los restantes brazos y acequias comprendidas en tierra de chovedat." ${ }_{46}$

Cabe considerar que la capacidad de modificación de las normas a nivel local, existe en la medida en que no afecta a la distribución colectiva y derechos de aguas de los regantes de otras zonas de riego. Como ya hemos comentado en el apartado 3.1.3, en el caso de la RAM, esto está garantizado mientras existe el sistema mixto de tanda y turno.

En cuanto a la distribución del agua, tenemos también constancia de la presencia de trabajadores encargados de la distribución del agua, de designación municipal y con gastos a cargo del ayuntamiento. El registro más antiguo se ha encontrado en Carpesa y data de $1792{ }^{47}$. En 1796 también se designan en Carpesa tres atandadores para diferentes acequias y se establece hacer bando para "que ningún vecino fuera osado a poner parada alguna en las acequias sin pertenecerle la tanda bajo la pena de una libra, y fuera tanda igualmente y baxo la misma pena no se puede poner por arriba parada alguna sin baxar a ver si riega alguno." ${ }_{48}$ Este caso muestra también la especificación, por escrito, de normas de riego que siguen vigentes en la actualidad.

En $1883^{49}$ se reúnen en Cases de Bárcena, las autoridades y más de 40 vecinos, de Valencia y Almássera, para nombrar atandador del bras de Xirivella . En $1945^{50}$ se designan en Museros seis arregladores con cargo al presupuesto municipal, lo que ocurre hasta 1960 donde se delega esta competencia en la recién creada Junta de arregladores y distribuidores de aguas, que actualiza la información sobre superficie regada y efectúa el cobro del cequiaje ${ }^{51}$. En algunos municipios la figura del atandador, arreglador o distribuidor de aguas ha persistido hasta la actualidad aun cuando la distribución del agua es hoy responsabilidad del síndico y la ejecuta un guarda, trabajador de la RAM.

El municipio de Massamagrell nos aporta un acuerdo municipal, en 1935, que aclara perfectamente como gestionaba el ayuntamiento las cuestiones relacionadas con el riego:

\begin{abstract}
"[...] a consecuencia de haber acordado la Junta de Gobierno de la Acequia de Moncada el cobrar directamente la imposición de tacha y cequiaje de dicha acequia, se estaba en el caso de proceder a una derrama entre los propietarios de tierras de regadio en este término municipal para satisfacer los gastos, de la dotación del acequiero subalterno, jornales custodia de aguas, escuras ordinarias y extraordinarias que se realicen, confección de costeros o buixets y demás gastos que traen la administración de las aguas; cuyo presupuesto de gastos teniendo en cuenta el formado años anteriores, importaría aproximadamente unas 2400 ptas y resultaría gravada la banegada a razón de 0,75 ptas por lo que propone se proceda al presupuesto y reparto de cequiaje para el corriente ejercicio de la cantidad expresada." ${ }_{52}$
\end{abstract}

\footnotetext{
46 Archivo Municipal de Puçol, Acta municipal del 20/5/1947.

${ }^{47}$ Archivo Municipal de Valencia, Carpesa 13/1, Documento N. ${ }^{\circ}$ 1, Libro de Deliberaciones y Acuerdos del lugar de Carpesa, 1792.

${ }^{48}$ Archivo Municipal de Valencia, Carpesa, 13/1, Documento N. ${ }^{\circ}$ 3, Libro de Deliberaciones y Acuerdos del lugar de Carpesa, 1796, 30/03/1796.

${ }^{49}$ Archivo Municipal de Valencia, 1889-97/ Sección 3ª B.IªH, Documento N. ${ }^{\circ}$ 30, 1883.

${ }^{50}$ Archivo Municipal de Museros, Acta municipal del 10/03/1945.

${ }^{51}$ Archivo Municipal de Museros, Acta municipal de 30/09/1960 y Acta municipal de 25/05/1961.

${ }^{52}$ Archivo Municipal de Massamagrell, Actas Municipales del 7/06/1935.
} 
Con estos antecedentes podemos afirmar que históricamente la RAM gestionó de facto el canal y el reparto del agua del Túria a las distintas demarcaciones en tanto que la gestión del agua dentro ya de cada término municipal era una cuestión municipal, aunque supervisada por la Junta de Gobierno de la RAM, por otra parte la gestión del extremal era exclusivamente municipal.

La RAM ejerce el liderazgo a la hora de defender los intereses generales de los regantes, lo podemos comprobar cuando en 1870 notifica al ayuntamiento de Meliana que: "en junta de propietarios, se nombren dos para que acudan a la Junta que ba de celebrarse en la Casa Comuna" "53. En Massamagrell se nombra en 1912 a un representante para que asista "a las conferencias que puedan originarse durante el corriente año ante el Gobernador Civil, Sr. Acequiero de la RAM u otras autoridades necesarias con el fin de resolver los conflictos que por escasez de agua puedan sobrevenir en el presente verano" ${ }_{54}$ y en 1927 el Ayuntamiento de Massamagrell, se reúne en sesión pública extraordinaria para dar a conocer un escrito del acequiero "en la que invita a esta Alcaldía y propietarios regantes de dicha acequia, a la asamblea que como reunión extraordinaria [...] en la que se tratará sobre el revestimiento del canal" "55. En 1955 tiene lugar una reunión en Moncada a la que asisten todos los alcaldes y que trata "la grave situación creada por la cesión del caudal de agua perteneciente a dicha real Acequia y regantes de todos los Municipios reunidos, a favor de otras acequias de la vega valenciana".

La elección de uno o dos representantes municipales, para la participación en este tipo de reuniones con el resto de municipios de la RAM, parece una manera práctica de articular una participación local con un coste relativamente moderado, teniendo en cuenta las dificultades del transporte en carro en una Comunidad de Regantes que abarca poblaciones a más de $30 \mathrm{Km}$ de longitud.

Respecto a la modificación de las ordenanzas, parece que en dos de los tres casos encontrados, esta responde a la petición de los regantes a las autoridades. En $1853{ }^{56}$ Isabel II deroga una orden relativa al nombramiento de acequiero y convoca a los municipios a una reunión para la elección de acequiero. En $1860{ }^{57}$ el Gobernador Provincial convoca a los

\footnotetext{
${ }^{53}$ Archivo Municipal de Meliana, Acta municipal del 1/03/1870.

${ }^{54}$ Archivo Municipal de Massamagrell, Actas Municipales del 12/6/1912.

${ }_{55}$ Archivo Municipal de Massamagrell, Actas Municipales del 22/12/1927.

56 "Enterada S.M. la Reyna... de la exposición que ha remitido VS de considerable numero de regantes de la Acequia de Moncada, pidiéndose se derogue lo mandado en Real Orden de 3 de Noviembre de 1847 acerca del nombramiento de Acequiero Mayor. Considerando que todos los regantes con las aguas de dicha acequia están interesados en la elección del mismo, S.M. se ha servido derogar la citada real Orden, y mandar que todos los regantes puedan intervenir en la elección de Acequiero mayor para lo qual los de cada Pueblo nombraran representante que concurra a elegir la persona de su confianza al Pueblo más céntrico de la Acequia ante cuyo alcalde se verificara la Elección. Al propio tiempo es la voluntad de S.M. que los Síndicos de la Acequia de Moncada manifiesten las modificaciones que debe sufrir la Ordenanz̧a de sus riegos, las que remitirá V.I, a este Ministerio con un informe [...] En cumplimiento de lo mandado por S.M. prevengo a V. que previa la oportuna publicación por medio de bandos y fijación de Edictos convoque para el día 30 del actual sin falta alguna a los propietarios regantes de la Acequia de Moncada en el término de ese Pueblo, a fin de que procedan a la elección de un representante que unido a los que nombrarán los demás pueblos interesados verifique después en el día y forma que determinare, el nombramiento de Acequiero." (Archivo Municipal de, Borbotó, 8. Caja 1, 30/10/1853.)

57 "Reunidas según convocatoria en la sala capitular de este Lugary diez horas de su mañana bajo la presidencia del Señor Alcalde del mismo Don Vicente Gimeno algunos propietarios regantes de este término que al margen se espresan en junta general, el Presidente declaró abierta la misma, y dispuso que por el infraescrito Secretario se leyese el oficio recibido del M.I.S.Gobernador de la Provincia en fecha 20 del que rige relativo a que en atención a una instancia dirigida a dicha Autoridad por los pueblos de Moncada, Alfara y Vinalesa, se reuna junta general en todos los pueblos regantes de la Acequia de Moncada, y nombren las mismas en cada localidad dos Comisionados, que reunidos en el edificio del gobierno Civil el dia 7 de Octubre próximo y diez horas de la mañana, bajo la presidencia del Sr. Gobernador procedan aclarar o reformar las ordenanzas en la parte relativa a la elección de síndicos y Acequiero: los que enterados de su contenido procedieron a dicho nombramiento resultando elegidos por pluralidad Tomas Zaragoza y Puchol y Francisco Marco vecinos de este pueblo. Terminando el objeto de la presente junta en mediodía...”" (Archivo Municipal de Meliana, Actas del 30/9/1860.)
} 
regantes para la modificación de las ordenanzas respecto a la elección de síndicos y acequiero. En $1896{ }^{58}$, durante la restauración borbónica, se tiene conocimiento de una tercera reunión relativa a la modificación de ordenanzas.

3.2.2 La designación municipal del síndico. La Junta de Gobierno de la RAM está constituida por 12 'síndicos' y un 'acequiero mayor' que actúa como presidente. Esta junta se encarga de llevar a cabo la administración de la acequia. Los síndicos son los representantes de los regantes de las diferentes zonas de la comunidad, y como requisito se exige que no tengan tierra en las acequias de 'La Vega de Valencia', condición que asegura la independencia de las decisiones de los miembros de la Junta de Gobierno ${ }^{59}$. La elección del acequiero mayor es indirecta y se realiza por votación de los 12 síndicos.

En los registros municipales se tiene constancia de que generalmente la persona designada representante de los regantes, solía ser el alcalde o algún concejal del término municipal a la cabecera del sistema, al que correspondía este derecho o era votado por los miembros del ayuntamiento. Jaubert de Passa ya indica que el síndico era el regidor mayor del pueblo (Jaubert de Passa 1823, p.192). En $1796{ }^{60}$ tenemos constancia de un caso en que el regidor mayor tenía tierra en las acequias de la Vega y no podía por tanto ser síndico, esto suscita una disputa por el cargo entre el alcalde y el regidor menor que se resuelve a favor del alcalde por haber tenido mejores relaciones con los poderes fácticos. En 1860, también se tiene constancia de la elección de un síndico al que votaban los miembros del gobierno del ayuntamiento en Meliana ${ }^{61}$.

En una sociedad mayoritariamente agrícola, es probable que cualquier alcalde o concejal, con casi toda seguridad, fuera regante y representara los intereses de las oligarquías agrarias. Ahora bien, la participación de la población local en la elección del equipo de gobierno municipal y en consecuencia del síndico, ha variado ampliamente a través del tiempo, llegando a la situación actual en la que el síndico se elige por democracia directa entre los regantes de su zona y el acequiero mayor es elegido por los síndicos.

Aunque parece que la figura del síndico posibilitaría el acercamiento de los problemas locales a una organización supramunicipal, los documentos consultados no dejan constancia de ello salvo excepciones ${ }^{62}$. Parece más bien que esta representación a nivel de RAM responde, por el contrario, a la necesidad de tener representación local para la toma de decisiones que afectan a la Comunidad de Regantes en su conjunto.

Por otro lado, parece verosímil que la gestión del riego a nivel municipal, mediante el síndico y el ayuntamiento, permitía que las reclamaciones o necesidades de locales fueran tenidas en cuenta y resueltas de acuerdo a las posibilidades locales (económicas, técnicas, so-

\footnotetext{
${ }^{58}$ Nombramiento de comisión para asuntos de la RAM: Se nombra a Juan Garibo Carbonell. Se trata de crear una Comisión para reformar los capitulos de las Ordenanzas.” (Archivo Municipal de Massamagrell, Actas del 15/3/1896.)

${ }^{59}$ Capítulo 66 de las Ordenanzas de la RAM: "Que ningún terrateniente ó regante de Tormos pueda ser síndico, veedor, ni cequiero, pues sería nulo su nombramiento" (Jaubert de Passa 1823, p.251).

${ }^{60}$ Archivo Municipal de Valencia, Carpesa, 13/1, Documento N. ${ }^{\circ}$ 3, libro de Deliberaciones y Acuerdos del lugar de Carpesa, 1796, 06/10/1796.

${ }^{61}$ Archivo Municipal de Meliana, Acta municipal de 13/04/1870.

62 "Igualmente por el señor presidente se manifestó a la Corporación tener que hacer presente a la Junta de Gobierno de la Real Acequia de Moncada se rieguen por igual la misma los pueblos de arriba como de abajo o sea Paterna como Puzol, con lo que se conformaron por unanimidad el que se llevara a efecto..." (Archivo Municipal de Meliana, Actas Municipales del 25/05/1877.)
} 
ciales, etc.). Además esta gestión local parece jugar también un papel importante como mecanismo de prevención y resolución de conflictos. No obstante, esto no implica necesariamente que exista una activa participación de la mayoría de los regantes en la resolución de este tipo de problemas sino más bien que históricamente han participado unos pocos, los propietarios regantes, es decir la clase económicamente dominante y los encargados de la gestión en el ámbito municipal. No obstante, los ayuntamientos atendían y resolvían las diferentes peticiones que presentaban los regantes.

\section{Conclusiones}

De manera general, los datos consultados en los archivos municipales muestran con claridad que las tareas de recaudación del cequiaje, limpieza de acequias, y reparto del agua dentro de las derivaciones del canal principal, se realizaban a escala municipal desde finales del siglo XVIII hasta principios del siglo XX. Es más, algunos municipios funcionaban como pequeñas comunidades de regantes, llegando incluso a disponer de ordenanzas propias.

Asimismo, cabe considerar que la capacidad de modificación de las normas a nivel local existe. Sin embargo, eso no implica necesariamente que existiera una participación de los usuarios, ya que generalmente la persona designada como representante de los regantes solía ser el alcalde o concejal, al que correspondía este derecho o era votado por los miembros del ayuntamiento, que en una sociedad agrícola, con casi toda seguridad, representaban los intereses de las oligarquías agrarias. Por otro lado, parece verosímil que la gestión del riego a nivel municipal, mediante el síndico y el ayuntamiento, permitiera que las reclamaciones o necesidades de locales fueran tenidas en cuenta y resueltas de acuerdo a las posibilidades locales. Cabe notar que cada municipio tiene asignado un tiempo determinado por lo que la concesión de derechos a escala municipal no afecta al resto de regantes.

En este contexto, la RAM ejercía el liderazgo a la hora de defender los intereses generales de los regantes y que gestionaba el canal y el reparto del agua del Túria a las distintas zonas de riego, en tanto que la gestión del agua dentro ya de cada término municipal era una cuestión municipal, aunque supervisada por la Junta de Gobierno de la RAM

Respecto a la definición de límites, los resultados muestran que, pese a que el espacio regado no ha permanecido totalmente constante, sí que han existido unos límites prefijados, fuera de los cuales la comunidad de regantes ha restringido la expansión del pleno derecho a riego. Estos límites son por un lado las tierras extremales (o con derecho a aguas sobrantes) y por otro, las zonas que requieren la elevación del agua. La comunidad sí ha permitido la expansión del riego dentro de los límites considerados como parte de la comunidad.

En resumen, la institución ha fijado unos límites que han permitido mantener una relación entre tierra regable y disponibilidad de recursos que se ha adaptado a las necesidades de los usuarios y donde es destacable la importancia de la gestión y toma de decisiones a escala local. Probablemente, la importancia del control por parte de la RAM fuera mayor en momentos de escasez severa o cuando el incremento del riego dentro de los límites establecidos perjudicara a los usuarios a la cola del sistema.

Agradecimientos. Nos gustaría agradecer la colaboración de la Real Acequia de Moncada, así como la de los Ayuntamientos a los que se ha recurrido para la búsqueda de información sin la cual este trabajo no habría sido posible. 


\section{Referencias}

Barceló, M. (1996): El diseño de espacios irrigados en Al-Andalus: un enunciado de principios generales. En: Barceló, M., Kirchner, H.; Navarro, C., Eds., El agua que no duerme: fundamentos de la arqueología bidráulica andalusí, Fundación Legado andalusí, Granada, pp. 51-70.

Burriel de Orueta, E. L. (1971): La Huerta de Valencia, zona sur. Estudio de Geografía Agraria, Valencia, Institución Alfonso el Magnánimo-Caja de Ahorros de Valencia.

Eau Securs 34 (2014): La longue route vers la gestion publique de l'eau et l'assainissement dans l'agglomération de Montpellier, http://eau34.ouvaton.org/index.php?id=63, consultada: 22.07.2014.

Garrido, S. (2011a): Las instituciones de riego en la España del este. Una reflexión a la luz de la obra de Elinor Ostrom, Historia Agraria, 53:13-42.

Garrido, S. (2011b): Governing scarcity. Water markets, equity and efficiency in pre-1950s eastern Spain, International Journal of the Commons, 5(2):513-534.

Garrido, S. (2012): Ampliación del regadío, regulación institucional y sostenibilidad en las huertas tradicionales de la España mediterránea, Investigaciones de Historia Económica, 8:94103.

Glick, T. F. (1970): Irrigation and society in medieval Valencia, Cambridge, Harvard University Press.

Glick, T.F. (2007): Paisajes de conquista. Cambio cultural y geográfico en la España medieval, Valencia, Universitat de València.

Hardin, G. (1968): Tragedy of Commons, Science, 162 (3859):1243--1248.

Jaubert de Passa, F. J. (1823): Voyage en Espagne, de 1816 a 1819, ou recherches sur les arrosages, sur les lois et costumes qui les régissent, sur les lois domaniales et municipales, considérés comme un puissant moyen de perfectionner l'agriculture française, París, Madame Huzard.

Maass, A. y Anderson, R. L. (1978): ... and the desert shall rejoice: conflict, growth and justice in arid environments, Cambridge, MIT Press.

Ostrom, E. (1990): Governing the commons: the evolution of institutions for collective action, Cambridge University Press, Cambridge.

Ostrom, E. (2011): El gobierno de los bienes comunes (2 ${ }^{\mathrm{a}}$ edición), Fondo de cultura económica, México.

Ruf, T. (2011): Le façonnage des institutions d'irrigation au XXe siècle, selon les principes d'Elinor Ostrom, est-il encore pertinent en 2010 ?, Nature, sciences et sociétés, 4:395-404.

Sales Martínez, V. (1986): El regadío en la demarcación de la Real Acequia de Moncada, Tesis de licenciatura, Universitat de València.

Sales Martínez, V. (1988): La cuestión del extremal en el regadío de la Real Acequia de Moncada. Cuadernos de Geografía, 44: 221-234.

Sales Martínez, V. (2000): Petits regs a l'Horta de València. Els assuts del Carraixet. Actes del Primer Congrés d'Estudis de l'Horta Nord Nord. Actes del I Congrés d'Estudis de l'Horta Nord Nord, Meliana 1997), Centre d'Estudis de l'Horta Nord, pp. 333-348.

Sales Martínez, V., Urzainqui Sánchez, S. (2011): Sobre una visura de la Séquia de Moncada en el segle XVI (1576). Actes del III Congrés d'Estudis de l'Horta Nord, Vol I. València, Universitat Politècnica, pp. 97-118. 
Sanchis Ibor, C. (2001): Regadiu i canvi ambiental a l'Albufera de València, Valencia, Universitat de València.

Torró, J. (2012): Les regions orientals d'al-Àndalus abans de la conquesta catalanoaragonesa. Una visió general, Catalan Historical Review, 5:143-157.

Torró, J. (2000): Pour en finir avec la Reconquête. L'occupation chrétienne d'al-Andalus, la soumission et la disparition des populations musulmanes (XIIe-XIIIe siècles), Cabiers d'Historie. Revue d'historie critique, 78:79-97.

Trawick, P., Ortega-Reig, M. y Palau-Salvador, G. (2014): Ecounters with the moral economy of water: convergent evolution in Valencia, WIREs Water, 1 (1):87-110. 